\title{
A SUBJETIVIDADE A PARTIR DA REFLEXÃO FILOSÓFICA \\ DE DELEUZE E GUATTARI
}

\author{
Patrícia Oliveira Lira \\ Yasmin Janaína Ferreira Marcos ${ }^{2}$
}

\begin{abstract}
RESUMO
A subjetividade tem sido concebida na tradição filosófica, nas ciências humanas de modo geral e na psicologia em particular com uma substancialidade que define uma suposta natureza humana. Através do pensamento de Gilles Deleuze e Félix Guattari, o conceito é reinventado e posto numa órbita de processualidade maquínica de produção de territórios, colocando em movimento uma ética do devir que provoca desvios nos padrões individuais e identitários. Cabe, então, interrogar o verbo Ser dos supostos sujeitos, subvertendo as lógicas dicotômicas que fazem da subjetividade uma fronteira demarcadora de uma interioridade em oposição a uma exterioridade. Os conceitos de Rizoma, Ritornelo e Devir suscitam uma desterritorialização da própria noção hegemônica de subjetividade de modo a operá-la como superfície vibrátil ao mesmo tempo não-visível e não-oculta.
\end{abstract}

Palavras-chave: Subjetividade. Agenciamentos. Rizoma. Ritornelo. Devir.

\begin{abstract}
Subjectivity has been conceived in the philosophical tradition, in the human sciences in general and in psychology in particular with a substantiality that defines a supposed human nature. Through the thought of Gilles Deleuze and Félix Guattari, the concept is reinvented and put into an orbit of mechanical processuality for the production of territories, setting in motion an ethic of becoming that causes deviations in individual patterns and identities. It is then necessary to question the verb Being of the supposed subjects, subverting the dichotomous logics that make subjectivity a frontier demarcating an interiority as opposed to an exteriority. The concepts of Rhizome, Ritornello and Becoming evoke a deterritorialization of the hegemonic notion of subjectivity itself in order to operate it as a vibrational surface at the same time non-visible and non-occult.
\end{abstract}

Keywords: Subjectivity. Assemblages. Rhizome. Ritornello. Becoming.

\footnotetext{
${ }^{1}$ Doutora em Psicologia. Professora Adjunta da Universidade de Pernambuco. patriciaolira@gmail.com.

${ }^{2}$ Graduanda em Psicologia pela Universidade de Pernambuco. marcosfyasmin@outlook.com.
} 
Em princípio, cada texto que se publica é um convite. Na escrita que segue, propomos uma partilha que nos faça sair dos muros, desmascarar algumas fronteiras que limitam nosso olhar, sobretudo nas linhas de segmentaridade acadêmicas com seus escopos, seus discursos e seus apegos tantas vezes pré-datados. Lançamo-nos na problematização da subjetividade, tema que, a despeito de reflexões filosóficas contundentes como é o caso dos trabalhos de Michel Foucault, particularmente em cursos como A hermenêutica do Sujeito (2010), foi como que patenteada pelo campo psi na pluralidade teórico-conceitual que lhe é própria.

Partimos, assim, da constatação do espectro hegemônico em torno desse conceito ao longo do século XX, para logo nos avizinharmos ao pensamento filosófico fruto do encontro entre Gilles Deleuze e Félix Guattari, provavelmente não por acaso acontecido na ressonância dos movimentos de 1968, onde a experiência subjetiva no mundo se fazia claudicar frente aos efeitos que o projeto moderno já sinalizava sobre os modos de vida e de subjetivação.

Propomos, então, algumas notas introdutórias que nos permitam desterritorializar a noção de subjetividade a partir de uma inspiração filosófica capaz de operá-la com outros intercessores, de modo a nos lançar para fora de nossa mais cara representação, qual seja, a de uma experiência subjetiva balizada pelo valor de intimidade que nos pressupõe livres e autônomos muito mais por uma questão de poder do que de potência, muito mais por competência moral do que por performance ética. Isso, evidentemente, exige de nós um deslizamento da lógica da representação do mundo para a aventura da invenção de mundos a partir de um "pensamento sem imagens" operado pela diferença. Exige o desalojamento de qualquer ordem dogmática que nos enraíze, embora sempre busquemos nos enraizar. Exige encarar o próprio ato de pensar como criação que produz rupturas no pensamento. Para Deleuze, a única criação verdadeira. (MAURÍCIO e MANGUEIRA, 2011). 


\section{Subjetividade e tradição moderna}

Talvez o aspecto que mais atue na caracterização de uma "natureza" humana seja o de uma determinação subjetiva. Desde muito cedo, aprendemos e somos instruídos sobre nosso distanciamento dos (outros) animais a partir de nossa competência operada na racionalidade. Trata-se de uma demarcação de naturezas que, ao nos identificar com o mundo animal, nos destaca dele a ponto de nos esquecermos das origens sujas que nos remetem aos céus, à terra, ao ar, à água e a todas as misturas possíveis do vivo com o mundo: suas respirações, suas palpitações, aquilo que transpira em nós, que queima ou que faz levitar, aquilo que nasce e aquilo que morre todos os dias ou de uma vez por todas um dia. A história do pensamento ocidental tem reiterado a ideia de vida e de mundo calcada na certeza de nossas representações. Crer que somos humanos porque somos racionais e sermos afetados por isso a partir de nossos espíritos darwinistas a fim de nos destacarmos mais e mais do mundo e de sua natureza suja, mestiça, imanente, parece nos colocar cada vez mais distantes dos fluxos intensivos que nos perpassam e nos produzem não de uma vez por todas, mas sempre e todas as vezes que acordamos, lembramos, comemos, respiramos, sentimos, fazemos, pensamos, somos, estamos. A síntese do caos erigida numa representação dos estados de coisas nos é cara, porque apazigua em nós a coexistência dos corpos, seus fluxos, intensidades e devires.

Talvez esse seja um dos maiores legados da modernidade e seu projeto cientificizante de subjetivação, que nos captura pela representação Una, estável e localizável do mundo e seus objetos e de nós mesmos, erigidos em nosso estatuto de sujeito, no mundo. $\mathrm{O}$ século $\mathrm{XX}$, enquanto grande corolário dos ideais iluministas, trouxe com ele todas as condições para que a subjetividade pudesse ser tecida pelas malhas duras da racionalidade científica. Primeiro, com a produção de uma experiência privatizada de subjetividade onde se dirá "cada cabeça é um mundo", mas, ainda, com a experiência de crise diante dessa subjetividade que, embora patente para os espíritos, toca o tempo todo o trágico da condição humana, naquilo que ele guarda de insondável, imensurável, intangível, ou seja, naquilo que pode fazer vacilar as 
certezas fabricadas pelo campo das inteligibilidades. (FIGUEIREDO e SANTI, 2002).

No bojo dessa tessitura de objetos e saberes a eles atrelados, a Psicologia emerge como campo específico, reclamando para si um estatuto científico, a fim de sistematizar e esquadrinhar a subjetividade tomada como objeto de investigação do ver e do escutar. Surge aí o que poderíamos considerar um novo ethos para a subjetividade, mas não necessariamente dado por um saber unificado e seguro de atribuição de sua verdade, haja vista a equivocidade que marca o campo da psicologia moderna desde a aurora do século XX. A subjetividade enquanto terreno da experiência privilegiadamente privatizada encontra abrigo ao mesmo tempo que esbarra na pluralidade teórico-prática do escopo que se esforça por operá-la.

De fato, a história da formulação da subjetividade como objeto das racionalidades privilegiado pela psicologia coloca em evidência uma dimensão ética, na medida em que evoca problemas de definição e dos modos de apreensão dos seus efeitos. Diversas matrizes conceituais irão determinar diferentes maneiras de abordar e interrogar o sujeito psicológico. No percurso epistemológico traçado por Figueiredo (1991), situamos, grosso modo, um eixo gravitacional que opera, de um lado, uma forte filiação ao positivismo lógico, berço inicialmente exaltado pela dita psicologia científica, cujo ethos abriga a subjetividade nas supostas certezas operadas pela inteligibilidade dos processos mentais; e, de outro lado, as abordagens que colocam em perspectiva o esforço crítico-interpretativo interessado menos na evidência do que na problematização dos efeitos subjetivos. De todo modo, resguardadas suas oposições, o amplo espectro da psicologia como herdeira da subjetividade, agora calcada na figura-objeto do sujeito moderno, mantém a hegemonia da consciência como grande legado em torno do qual se organizam suas elaborações sejam elas mais ou menos observáveis ou profundas. A psicologia hegemônica mantém, de uma maneira ou de outra, a consciência como guardiã da verdade.

O impacto epistemológico operado pela psicanálise torna o campo ainda mais complexo. Sistematizada paralelamente às psicologias, a psicanálise produz uma ruptura ainda mais radical no campo das humanidades. Inicialmente com Freud e, mais tarde, com Lacan, a fé nas profundezas in- 
conscientes como lugar onde habita a verdade do sujeito vai fundo no questionamento do estatuto inteligível da subjetividade, à medida que a coloca numa órbita de descentramento radical da consciência. Daí a inversão de Lacan à máxima cartesiana do cogito: "sou onde não me penso, portanto penso onde não sou" (GARCIA-ROZA, 1996, p. 23). A verdade agora reencontrada fora da consciência, mas sempre a verdade buscada como via possível de significação do sujeito atado a uma representação de si. Uma verdade fundada na falta e na culpa, uma fórmula bastante eficiente para dar conta do modo de subjetivação moderno.

Entretanto, nas últimas décadas do século XX, o Sujeito e sua verdade passa a ser operado por outras vias: o pai de família, o chefe da empresa, o professor na escola não são mais garantes civilizatórios capazes de oferecer referências universalizantes de uma representação do mundo e dos seus objetos desejáveis. A própria psicanálise passa a buscar novas inscrições para os efeitos dos processos inconscientes na produção subjetiva, entendendo que agora o laço social exige que cada um responda de modo singular e bem-sucedido ao "che vuoi" lacaniano: o que o outro quer de mim? Sem dúvida, mais um passo adiante das elaborações psicanalíticas, todavia assegurando a manutenção do status quo do Sujeito como eixo gravitacional do desejo que se opera pela filiação ao dito desejo do Outro a partir de uma falta radical de existir que pede sempre uma significação sobredeterminada pelo oráculo inconsciente.

Notadamente ao longo da segunda metade do século XX, onde floresce uma multiplicidade de saberes e práticas como desdobramentos das experiências de guerra e devastação produzidas pelas sociedades científicoindustriais, o escopo investigativo acerca da subjetividade se expande e se torna ainda mais problemático. $\mathrm{O}$ fator ético-político ganha mais força nas abordagens acerca da natureza humana até então concebida hegemonicamente como oposição fronteiriça entre exterior/interior, dentro/fora, corpo/ mente, afetos/razão, etc. Desde a psicologia social, principalmente no seu enfoque sociológico, passando pelas articulações entre psicanálise e ciências sociais até a análise institucional francesa e a discussão suscitada por filósofos como Foucault, Deleuze, Guattari, entre outros, a subjetividade passa a ser considerada mais em sua posição de processo construído a partir das 
questões sociopolíticas e históricas do que em seu estatuto de substância estável e fronteiriça das oposições localizáveis.

\section{Subjetividade maquínica e agenciamentos}

Félix Guattari marcou o campo de reflexões acerca da subjetividade a partir de duas vertentes nas quais atuou de modo intenso. De um lado, uma militância política extremamente engajada, de outro, uma atividade clínica pulsante marcada pelo contexto revolucionário que ensejou inovações importantes na clínica psicopatológica a partir do que veio constituir a Psicoterapia Institucional francesa, movimento emblemático da reforma psiquiátrica europeia. Desse modo, sua produção intelectual, que convergiu para o encontro com Deleuze na efervescente experiência de maio de 68 em Paris, é marcada por uma ênfase na ideia de que a subjetividade é uma produção heterogênea atravessada por instâncias individuais, coletivas e institucionais. O caráter processual da subjetividade, para ele, não reconhece nenhuma instância que atue como determinação causal unívoca. Guattari, que vive uma importante intercessão com a psicanálise lacaniana durante um longo período, passa a subverter a própria noção de inconsciente, retirando dela seu estatuto de sobredeterminação fundamental de uma estruturação psíquica.

Para ele, a subjetividade é mais próxima de um processo estético onde se cria uma composição heterogênea de si. Ou seja, a subjetividade não é determinada por uma instância ou por instâncias "cristalizadas em complexos estruturais", mas é criada do mesmo modo que "um artista plástico cria novas formas a partir da palheta de que dispõe". (GUATTARI, 2012, p. 17). Em outras palavras, o que ele propõe é que trabalhar a noção de subjetividade exige um deslocamento dos "paradigmas cientificistas" para "paradigmas ético-estéticos". Isso recoloca o problema da subjetividade no âmbito da reflexão filosófica.

A subjetividade é sempre produzida. Ela não está dada como substância. Ela não nasce das superestruturas que supostamente nos originaram pelos sistemas genéticos, pelos ecossistemas ou por romances familiares, dos deuses, dos partidos políticos ou de ideologias. A subjetividade, apesar 
de estabilizada pelas certezas identitárias atreladas a essas superestruturas, sejam elas genéticas, fisiológicas ou sociais, funciona mais do que é. Ela funciona de modo maquínico e processual, como efeito dos agenciamentos de enunciação onde se operam todas as supostas estruturas. A subjetividade como processo se produz no deslizamento. Não se trata de dizer "você é isso ou aquilo". Trata-se de agenciamentos maquínicos que produzem efeitos de subjetividade sempre transitórios em vias de acontecimento. Em outras palavras, para além da linguagem enquanto inscrição simbólica e de representação, a subjetividade é uma questão semiótica onde atuam elementos heterogêneos:

Os processos de subjetivação ou de semiotização não são centrados em agentes individuais (no funcionamento de instâncias intrapsíquicas, egoicas, microssociais), nem em agentes grupais. Esses processos são duplamente descentrados. Implicam o funcionamento de máquinas de expressão que podem ser tanto de natureza extrapessoal, extraindividual (sistemas maquínicos, econômicos, sociais, tecnológicos, icônicos, ecológicos, etológicos, de mídia, ou seja, sistemas que não são mais imediatamente antropológicos), quanto de natureza infra-humana, infrapsíquica, infrapessoal (sistemas de percepção, de sensibilidade, de afeto, de desejo, de representação, de imagem e de valor, modos de memorização e de produção de ideias, sistemas de inibição e de automatismos, sistemas corporais, orgânicos, biológicos, fisiológicos e assim por diante)." (GUATTARI e ROLNIK, 2013, p. 39).

Diante disso, a subjetivação passa pela produção de territórios, na medida em que estes agem como configurações subjetivas que abrigam núcleos que poderíamos chamar de identitários. O território seria "o conjunto dos projetos e das representações nos quais vai desembocar, pragmaticamente, toda uma série de comportamentos, de investimentos". (GUATTARI e ROLNIK, 2013, p. 388). Mas, atenção: a subjetividade como agenciamento passa pelo território, atravessa-o no sentido sempre para fora. Essa passagem é um atravessamento. Ela se põe na borda, como superfície de contato com o fora, sempre em potência de desterritorializar-se para compor outra coisa. Em outras palavras, a subjetividade, enquanto experiência territorial transpassa o território, sem que se ache encontrada por meio de seus limites. Enquanto campo de territorialidade, ela se engendra pelos agenciamentos maquínicos de corpos (máquinas sociais, corpos humanos, corpos animais, corpos cósmicos) e pelos agenciamentos coletivos de enunciação (expres- 
sões e estilos mediados pelo regime de signos). É na conjugação dos agenciamentos nessas diferentes modalidades que o território se compõe. É nessa condição de agenciamento que ele pode ser, também, desterritorializado e reterritorializado. Não há composição de território sem que forças de desterritorialização e de reterritorialização ajam sobre ele (HAESBAERT e BRUCE, 2002). É ainda nessa intercessão dos agenciamentos dos corpos e dos signos que o território diz respeito ao pensamento e ao desejo e, portanto, à subjetividade em sua qualidade maquínica de abertura/fechamento/abertura.

Para pensar o território, Deleuze e Guattari (2012a) tomam a dimensão rítmica e melódica que produz o efeito musical do ritornelo: refrão, cantiga que sempre volta a uma frase melódica. A partir da repetição que nunca volta ao mesmo, o ritornelo é tomado como demonstração de forças que operam na produção de territórios subjetivos. Na música, o ritornelo repete, mas é nessa repetição onde se encontra a potência de produção de novas ênfases, de modo que elas inscrevam uma diferença na repetição. $\mathrm{O}$ modo de ritornelo trabalha nesse deslizamento de se identificar, ou seja, de voltar ao mesmo, ao idêntico e, ao mesmo tempo, produzir aberturas de experimentação para uma outra coisa, um outro modo de compor, um jeito diferente de habitar o território. É como voltar para casa depois de uma viagem. A casa não é mais a mesma embora o seja; nós também compomos nova natureza.

Ora se vai do caos a um limiar de agenciamento territorial: componentes direcionais, infra-agenciamento. Ora se organiza o agenciamento: componentes dimensionais, intra-agenciamento. Ora se sai do agenciamento territorial, em direção a outros agenciamentos, ou ainda a outro lugar: interagenciamento, componentes de passagem ou até de fuga. E os três juntos. Forças do caos, forças terrestres, forças cósmicas: tudo isso se afronta e concorre no ritornelo. (DELEUZE e GUATTARI, 2012a, p. 124).

Assim, o conceito do ritornelo, enquanto modo de agenciamento, evoca sempre um trinômio: territorialização/ desterritorialização/ reterritorialização. Dito de outro modo, a produção de subjetividade está ligada à composição de territórios pela conjugação de agenciamentos nem dentro nem fora, mas entremeios. Se o que define o território é a demarcação, o fincar das placas de pertencimento, o que o produz é o caos. Não se faz território sem ter a referência de estar desterritorializado. A subjetividade opera, portanto, entre o idêntico e a diferença por meio da multiplicidade dos agen- 
ciamentos. Ela trabalha por meio da diferença que se agita no plano de imanência, "gerando sempre mais diferença e tornando tudo exterior a tudo". (NEVES, 2009, p. 201).

Nesse ponto, tocamos numa questão importante que é a noção de identidade como a experiência subjetiva que nos torna idênticos, que nos assegura uma certa estabilidade sobre quem somos, que nos assegura na órbita do verbo ser das coisas. Todavia, a subjetividade maquínica está sempre nesse campo de superfície que faz fronteira com o caos, com a abertura, com a diferença que nos remete ao devir e a impermanência da vida em nós e de nós no mundo. Isso produz uma inversão importante que vai do nosso estatuto enquanto sujeitos individuais a uma condição de singularidade que nos põe na teia da diferença que se destaca da identidade individuo/grupo. Guattari propõe pensarmos em termos de subjetividades singularizadas opondose à produção de indivíduos como resultado de uma produção de massa serializada, registrada, modelada:

A subjetividade está em circulação nos conjuntos sociais de diferentes tamanhos: ela é essencialmente social, e assumida e vivida pelos indivíduos em suas existências particulares. O modo pelo qual os indivíduos vivem essa subjetividade oscila entre dois extremos: uma relação de alienação e opressão, na qual o indivíduo se submete à subjetividade tal como a recebe, ou uma relação de expressão e de criação, na qual o indivíduo se reapropria dos componentes da subjetividade, produzindo um processo que eu chamaria de singularização. (GUATTARI e ROLNIK, 2013, p. 42).

Importante, pois, distinguir indivíduos de singularidades. A lógica capitalística, ao colonizar a subjetividade pela padronização do desejo, captura imaginariamente o indivíduo na crença de que ele é, ou seja, concedendo-lhe a certeza de que ao ser quem ele é (identidade) ele está bem situado e legitimado no âmbito das trocas sociais, na economia do desejo operador do consumo. Nesse sentido, Foucault, no prefácio da edição americana do livro O Anti Édipo (1997), diz “é preciso desindividualizar”, ou seja, sair das amarras da individuação massificante que diz como se ter qualidade de vida. Singularizar estaria no fluxo da resistência, mas de uma resistência ativa, na medida em que operaria a criação de novos mapas existenciais. 
Eu oporia a essa máquina de produção subjetiva a ideia de que é possível desenvolver modos de subjetivação singulares, aquilo que poderíamos chamar de "processos de singularização", uma maneira de recusar todos esses modos de encodificação preestabelecidos, todos esses modos de manipulação e de telecomando, recusá-los para construir modos de sensibilidade, modos de relação com o outro, modos de produção, modos de criatividade que produzam uma subjetividade singular. Uma singularização existencial que coincida com um desejo, com um gosto de viver, com uma vontade de construir o mundo no qual nos encontramos, com a inauguração de dispositivos para mudar os tipos de sociedade, os tipos de valores que não são os nossos. (GUATTARI e ROLNIK, 2013, p.22)

O inconsciente sai do lugar de representação que lhe confere status de "tesouro de significantes" para ser traduzido como território de produção de mundos, ou, em outras palavras, como usina que produz territórios existenciais movida pela imanência da vida. Estamos sempre e incessantemente em potência de engendrarmos modos de existir mais singularizantes em meio aos apelos avassaladores da massificação capitalista que insiste em manufaturar o desejo.

O traço comum entre os diferentes processos de singularização é um devir diferencial que recusa a subjetivação capitalística. Isso se sente por um calor nas relações, por determinada maneira de desejar, por uma afirmação positiva da criatividade, por uma vontade de amar, por uma vontade de simplesmente viver ou sobreviver, pela multiplicidade dessas vontades. É preciso abrir espaço para que isso aconteça. O desejo só pode ser vivido em vetores de singularidade. (GUATTARI e ROLNIK, 2013, p. 56).

Cada território existencial para se compor, produzindo suas cartografias, requer o desejo enquanto força que põe os corpos à espreita de acontecimento. É aí onde o desejo nos põe em superfície de efetuação da vida, engendrando novos territórios que nos levam sempre a nos repetir de modo diferente tal qual no ritornelo.

\section{Subjetividade de borda}

Nesse ponto, encontramos Deleuze (2013) que retoma a fórmula do poeta Paul Valéry, “o mais profundo é a pele”, remetendo-nos justamente à subversão de uma visão simplista e cristalizada das superfícies. A partir dela, ele desconstrói a oposição entre superfície e profundidade, recolocando o problema como uma questão de inscrição, e não de não-visível e não- 
oculto. Ao retomar a figura da pele em conjunção de superfície e de profundidade, Deleuze evoca a experimentação contraposta à interpretação: "Jamais interprete, experimente..." (p. 113). Nessa perspectiva, não se trata de pensarmos a subjetividade como superfície de demarcação, mas como superfície de inscrição, porque a questão não está em interpretar a partir de algo não-visível, mas de experimentar a partir da superfície enquanto inscrição dos acontecimentos.

Essa metáfora da pele é retomada por Rolnik (1997) como superfície que se dobra e desdobra, operando a trama subjetiva que, embora suscite uma simples equação de fronteira entre oposições (dentro/fora, indivíduo/ grupo, eu/outro, etc.), é mais profunda e complexa se conjugada com o plano intensivo dos afetos que fazem vacilar seus fluxos. Nesse sentido, a ideia de superfície toca a subjetividade em seu caráter "maquínico" do qual fala Guattari, ou seja, uma produção que está intimamente ligada aos territórios enquanto zonas de agenciamentos de naturezas heterogêneas que se conjugam produzindo efeitos de singularização.

Se tomarmos a pele como mera membrana de fronteira entre o dentro e o fora, como emblema da demarcação de territórios estáveis e localizáveis, resguardando-nos face ao pavor do infinito tal como assegura a alguns a certeza de que a terra é plana, ela se põe morna, inerte, sem pulsação, sem transpiração, nem suor, nem arrepios. A pele como tessitura vibrátil da própria vida em nós, experimenta a todo momento, marcando uma territorialidade corpórea, sempre no rastro de uma outra coisa: campo de abrigo sossegado e, ao mesmo tempo, campo de aberturas e devires, de tal modo que o corpo já não é mais o mesmo depois de experimentar cheiros, paladares, movimentos ou ventanias. A pele é lançada para fora do corpo, desterritorializando-se de sua qualidade de órgão, mesmo que ele seja o maior. A pele, aqui, involui a sua condição "menor", lançando-se no "corpo-semórgãos"; esse corpo que recusa o sistema orgânico para abrir-se aos fluxos que vazam por entre os sulcos, fissuras e membranas. Ele é "um conjunto de válvulas, represas, comportas, taças ou vasos comunicantes" (DELEUZE e GUATTARI, 2012b, p. 16). O corpo-sem-órgãos se produz justamente quando faz desaparecer, pela experimentação, o corpo orgânico como sistema demarcado pela síntese de uma territorialidade. A pele desse corpo se despoja 
de sua condição orgânica para se tecer enquanto pura superfície por onde fluxos se experimentam na medida em que escorrem e vazam, expandindo o próprio corpo enquanto potência. É da pele que Guattari fala quando sugere o arrancar-se de um caos a uma caosmose a partir daquilo que um corpo pode demarcado pela pele que situa o dentro e o joga para fora ao mesmo tempo:

Tratar-se-ia de reconciliar o caos e a complexidade. (...) O mundo só se constitui com a condição de ser habitado por um ponto umbilical de desconstrução, de destotalização e de desterritorialização, a partir do qual se encarna uma posicionalidade subjetiva. Sob o efeito de um tal foco de caosmose, o conjunto dos termos diferenciais, das oposições distintivas, dos polos de discursividade é objeto de conectividade generalizada, de uma mutabilidade indiferente, de uma desqualificação sistemática. Esse vacúolo de descompressão é ao mesmo tempo núcleo de autopoiese sobre o qual se reafirmam constantemente e se formam, insistem e tomam consistência os Territórios existenciais e os Universos de referência incorporais. (GUATTARI, 2012, p. 94).

Assim, a pele enquanto superfície vibrátil, visível e não visível ao mesmo tempo, leva-nos um pouco mais à vizinhança entre as noções de subjetividade e de borda. A pele enquanto produção de territorialidades subjetivas nos garante o dentro e ao mesmo tempo nos lança para fora. " $\mathrm{O}$ dentro detém o fora e o fora desmancha o dentro" (ROLNIK, 1997, p.27), na medida em que, na territorialização, agem forças que apaziguam, desintensificando as forças do fora, tal qual um ritornelo, desenhando, aí, uma experiência de si territorializada a partir da ancoragem em um dado microcosmo que nos faz ver, sentir e agir a partir de um corpo físico, imagético, social, político, etc. Mas, também, as forças do fora, em permanente agitação, não cessam de perfilar o diagrama corpóreo, desfazendo as dobras que agregam o dentro e produzindo uma outra territorialidade subjetiva. Quando nos reterritorializamos já não somos mais os mesmos: "É só nesse sentido que podemos falar num dentro e num fora da subjetividade: o movimento de forças é o fora de todo e qualquer dentro, pois ele faz com que cada figura saia de si mesma e se torne outra. O fora é um 'sempre outro do dentro', seu devir." (ROLNIK, 1997, p. 27). Aliás, o fechamento que a identidade confere é justamente na tentativa esforçada em conter as forças do fora que tocam as bordas e produzem rupturas na película subjetiva. Há quem aposte num modo estéti- 
co de operar essas forças, abrindo-se para novas modulações de si. Há quem não as suporta, recrudescendo nas certezas identitárias cada vez que as forças do fora batem a sua "aorta".

A subjetivação como processo de borda diz respeito a uma ética do devir que exige um outro movimento, menos arborescente e mais rizomático: "muitas pessoas têm uma árvore plantada na cabeça, mas o próprio cérebro é muito mais uma erva do que uma árvore." (DELEUZE e GUATTARI, 2011. p. 34). O devir, enquanto campo incessante de abertura para o "outrarse", não compõe com a ideia de enraizamento, de fixidez ou de verticalidade. Para devir, é necessário fugir pelas bordas, escapar por todos os lados, a qualquer entrada ou por qualquer saída. Na geografia subjetiva inspirada na figura do Rizoma, as forças ganham velocidade e se exercem em processo de devir, sempre transitório, passante, vazando por todos os lados, para dentro e para fora em ritornelos. Assim, a subjetividade rizomática está sempre transpirando pelas bordas, sempre em processo e sempre em potência de tornar-se. Ela não se impõe como uma natureza de Ser, mas como potência de devir. Ela é uma ética.

Por que é tão difícil? É desde logo uma questão de semiótica perceptiva. Não é fácil perceber as coisas pelo meio, e não de cima para baixo, da esquerda para a direita ou inversamente: tentem e verão que tudo muda. [...] O importante não é que os fluxos produzam "Uno ou múltiplo", não estamos mais nessa: há um agenciamento coletivo de enunciação, um agenciamento maquínico de desejo, um no outro, e ligados num prodigioso fora que faz multiplicidade de toda maneira. (DELEUZE e GUATTARI, 2011, p. 46).

A ética do devir performatiza por meio de rizoma. O devir permite à subjetividade escapar das teias imaginárias que buscam a síntese almejada pelo ideal de Sujeito psíquico. Quando Deleuze e Guattari tomam a noção de devir, é de uma ética de borda que tratam, daquilo que ganha velocidade na borda e escapa de uma filiação imaginária. Diante disso, os autores provocam nossos perceptos e afectos sempre na direção contrária da involução, abandonando o anseio pelo estatuto evolutivo do homem: devir-animal, devir-criança, devir-mulher. É sempre no menor dos estados que reside o devir-intenso. É sempre no fio mais tênue onde se ganha velocidade de potência. É justamente nessa linha sutil onde se faz vacilar o eu e todas as certezas subjetivas capturadas pelo semblante: "Devir é um verbo tendo toda 
sua consistência; ele não se reduz, ele não nos conduz a 'parecer', nem 'ser', nem 'equivaler', nem 'produzir'. ” (DELEUZE e GUATTARI, 2012a, p. 20).

Ou seja, nessa ética, a subjetividade se opera não por semelhança ou por características, mas por sua potência de "expansão", de "ocupação" e de "contágio". Muito mais como multiplicidade definida por "intensão" do que por compreensão. Mais uma vez insistimos: na subjetividade de borda, não se trata do ser isso ou aquilo, mas do devir em potência. A subjetividade de borda enquanto devir se situa, então, nas profundezas das superfícies de contato. O "eu" é uma variação, uma territorialidade transitória, fabricada pela simbiose de combinações entre naturezas sempre heterogêneas. Ele "é apenas um limiar, uma porta, um devir entre duas multiplicidades." (DELEUZE e GUATTARI, 2012a, p. 34/35). O próprio eu pode ser um devir quando o verbo "ser" abandona-se da forma e ganha força. O problema está em erigir o Sujeito como dogma, sequestrando o eu de sua condição de passagem ou de abrigo no meio de passagens. O eu como paragem, estadia, e não como estábulo.

Não é de se espantar, a tal ponto o devir e a multiplicidade são só e uma mesma coisa. Uma multiplicidade não se define por seus elementos, nem por um centro de unificação ou de compreensão. Ela se define pelo número de suas dimensões; ela se divide, não perde nem ganha dimensão alguma sem mudar de natureza. Como as variações de suas dimensões lhe são imanentes, dá no mesmo dizer que cada multiplicidade já é composta de termos heterogêneos em simbiose, ou que ela não para de se transformar em outras multiplicidades de enfiada, segundo seus limiares e suas portas. (DELEUZE e GUATTARI, 2012a, p. 34).

A subjetividade de borda é, também, uma questão de micropolítica. Não que ela exclua o plano macropolítico. Para Deleuze e Guattari (2012b), não há essa dicotomia, mas uma coexistência entre segmentaridades macropolíticas (molar) e micropolíticas (molecular) que atravessam os estados de coisa. Entretanto, enquanto processualidade que se abre em potência para rupturas e desvios, a subjetividade fabricada pelo plano de imanência em suas intensidades e afecções toca sensivelmente a análise micropolítica. É pelas bordas que se vai produzindo devires entre os territórios compostos na heterogênese das multiplicidades. Como pensar o território sem considerar 
os arranjos micropolíticos que o provocam, o definem e o desmancham incessantemente?

Enquanto "fenômeno de borda", a subjetividade singularizada, fruto de uma estética de territorialidades, não procura instâncias que a definam de um modo linear e causal. Pelo contrário, na micropolítica onde ela atua, a qualidade é de uma "política dos devires-animais", que querem sempre escapar dos agenciamentos hegemônicos da grande família, do Estado, da religião. Esses devires serpenteiam os modos de vida minoritários, sempre tateando nas bordas das grandes superestruturas que querem capturar o eu e dizer definitivamente quem somos, tornando-nos ao mesmo tempo dóceis e duros. Em outras palavras, a subjetividade de borda é uma questão de liberdade. Liberdade não como ideal apreendido pela captura imaginária moderna que nos prometeu felicidade de autonomia e independência por meio da competência demonstrada pelo poder de domínio do mundo. Mas, uma liberdade como produção de "uma vida" sem promessas, capaz de criar conexões e alianças para a invenção e exploração indefinida do imaginário na criação de mundos possíveis.

Finalmente, a subjetividade maquínica, desejante, alquímica, singularizada, tateia sempre pelas bordas porque é aí onde ela produz multiplicidade como puro devir. Na borda é onde tudo acontece: desterritorialização do "Outsider" que bordeja os territórios, rompendo para fora as transformações de devir, de modo a inventar incessantemente novas multiplicidades. (DELEUZE e GUATTARI, 2012a).

\section{Considerações Finais}

A subjetividade foi capturada, no percurso da história do pensamento ocidental, pela imagem ancorada na ideia de uma substância que se forma em nós e que demarca nossa experiência no mundo pela dicotomia interior/ exterior. Nessa captura, tornamo-nos apegados e dependentes do verbo "ser" atribuível a todos e a cada um de nós na modalidade de indivíduos pertencentes a um grupo. Pertencer a uma "terra" é a atribuição da subjetividade operada como pensamento que delimita um lugar determinante para nossa existência de uma maneira supostamente apaziguável. Que haja uma refle- 
xão revolucionária sobre o que somos, no sentido de nos colocarmos na trilha do que podemos nos tornar parece a grande injunção ética do pensamento filosófico de Deleuze de Guattari.

Quando consideramos a subjetividade não como substância, mas como heterogeneidade produzida pela composição de agenciamentos capazes de criar uma geografia de nossa experiência no mundo, parece mais possível tomarmos as rédeas de nossa vida, não no sentido de dominá-la, mas na perspectiva estética de inventá-la. “(...) tentem e verão que tudo muda.” (DELEUZE e GUATTARI, 2011, p. 46). A subjetividade, nessa perspectiva, não está aí para ser compreendida ou apreendida por especialismos que a interpretem, mas para se intensificar na duração da experimentação de si e do mundo ou de si no mundo ou do mundo que se efetua em cada um consigo. Esse si não significa uma unidade individual compondo o mundo, mas um território existencial que vaza das individualidades. Trata-se de subjetividades singularizadas que se destacam das multidões porque ganham potência nas bordas, no entremeio das zonas de vizinhança e, por bordejarem, são capazes de operar uma estética territorial sempre em estado de devir. O modo pelo qual os autores que suscitaram o presente texto fazem essa proposição, coloca, portanto, a subjetividade como uma ética. É uma provocação.

\section{Referências Bibliográficas}

DELEUZE, G. Conversações. $3^{\mathrm{a}}$ ed. São Paulo: Editora 34, 2013.

DELEUZE G. e GUATTARI, F. Mil Platôs: Capitalismo e Esquizofrenia 2, vol. 1. São Paulo: Editora 34, 2011.

DELEUZE, G.; GUATTARI, F. Mil Platôs: Capitalismo e Esquizofrenia 2, vol. 4. São Paulo: Editora 34, 2012a.

DELEUZE, G.; GUATTARI, F. Mil Platôs: Capitalismo e Esquizofrenia 2, vol. 3. São Paulo: Editora 34, 2012 b.

FIGUEIREDO, L. C. M. e SANTI, P. L. R. Psicologia, uma (nova) introdução: uma visão histórica da psicologia como ciência. São Paulo: EDUC, 2002.

FIGUEIREDO, L. C. M. Matrizes do pensamento psicológico. Petrópolis, RJ: Vozes, 1991. 
FOUCAULT, M. A hermenêutica do sujeito: curso dado no Collège de France (1981/1982). $3^{\text {a }}$ ed. São Paulo: Editora WMF Martins Fontes, 2010.

FOUCAULT, M. Preface in: Gilles Deleuze e Félix Guattari. Anti-Oedipus: Capitalism and Schizophrenia, New York, Viking Press, 1977, pp. XI-XIV. Traduzido por wanderson flor do nascimento. Disponível em: $<\mathrm{http}$ ://www.elearnspace.org/Articles/connectivism.htm $>$. Acesso em: 20/05/2020.

GUATTARI, F. Caosmose: um novo paradigma estético. $2^{\mathrm{a}}$ ed. São Paulo: Editora 34, 2012.

GUATTARI, F.; ROLNIK, S. Micropolítica: cartografias do desejo. $12^{\mathrm{a}}$ ed. Petrópolis, RJ: Vozes, 2013.

HAESBAERT, R.; BRUCE, G. A desterritorialização na obra de Deleuze e Guattari. Revista GEOgraphia/UFF, v. 4, n. 7, p. 7-22, 2002.

MAURÍCIO, Eduardo; MANGUEIRA, Maurício. Imagens do pensamento em Gilles Deleuze: representação e criação. Fractal: Revista de Psicologia, v. 23, n.2, p. 291-304, Maio/Ago, 2011.

NEVES, C. A. B. Gilles Deleuze e Política: interferências nos modos de se estar nos verbos da vida. In: TEDESCO, S. e NASCIMENTO, M. L. Ética e Subjetividade: novos impasses no contemporâneo. Porto Alegre: Sulina, 2009.

ROLNIK, S. Uma insólita viagem à subjetividade: fronteiras com a ética e a cultura. In: LINS, D. S. (Org.). Cultura e subjetividade. Campinas, SP: Papirus, 1997. 